\title{
Food deprivation and reactivity to shock
}

ROBERT J. BLANCHARD ANO D. CAROLYN BLANCHARD UNIVERSITY OF HAWAII, HONOLULU, HAWAII

Thirty-two albino rats, under no deprivation or under severe food deprivation, were given 10 series of 12 different shock intensities, using the method of constant stimuli. Their reactions were classified into several categories. For the vocalization category, thresholds were significantly higher for the deprived group while no differences were obtained on flinch or jump thresholds.

Kendler (1965) has suggested that one effect of an increase in motivation may be to lower stimulus thresholds. However, Griffiths (1962), using single 0, 12, and $24 \mathrm{hr}$. deprivation periods, found a negative relationship between hunger and reactivity to shock in the albino rat. In this study, vocalization, urination, defecation or "any vigorous movement" was used as an indication of the noxiousness of the shock.

In a study of the effects of shock intensity on the reactions of non-deprived rats, Kimble (1955) has indicated that typical reactions to shock vary with stimulus intensity, with a predominance of flinch responses to low shock intensities, and jump responses to high intensities. Moreover, Harvey \& Lintz (1965) have demonstrated that certain subcortical lesions can decrease jump thresholds, without altering flinch thresolds.

Since no direct comparison can be made between the single response category used by Griffiths, and the flinch and jump categories of Kimble, it is obvious that changes in the type of response to shock could occur with increase in hunger, without being appropriately reflected in a threshold for "any vigorous movement." Accordingly, the present experiment attempts to compare flinch and jump thresholds for rats under zero and severe food deprivation conditions. A further category, vocalization, which was used by Harvey and Lintz, is also included.

Method

The Ss were 32 female Holtzman derived rats, from the colony maintained by the University of Hawaii Psychology Department. They were 90-120 days old at the beginning of the experiment. Sixteen randomly selected Ss were placed on a 23-1/2 hr. deprivation schedule, and weighed every other day for a 10 day period before the experiment. The remaining $16 \mathrm{Ss}$ were given ad lib access to food and water, but were weighed at the same times as the deprived animals.

During testing, each $\mathrm{S}$ was placed in a Grason-Stadler operant conditioning chamber, and allowed 3-5 min. to explore. Shocks were presented through an E1064GS shocking source. Twelve stimulus intensities $(.05, .10$, $.20, .30, .40, .50, .60, .80,1.00,1.30,1.60$, and $2.00 \mathrm{ma})$ were used. Stimulus duration was $.2 \mathrm{sec} .$, and the average interstimulus interval was $10 \mathrm{sec}$. Order of presentation was random within each block of trials, with each stimulus intensity being presented once per trial block, for a total of 10 trial blocks. Jumps, flinches, and vocalizations were judged according to the criteria used by Harvey and Lintz. The $E$ who judged these responses did not know the stimulus intensity on any given trial, or the S's experimental condition.

Results

Figure 1 presents the proportion of flinch, and jump, responses of the two groups as a function of stimulus

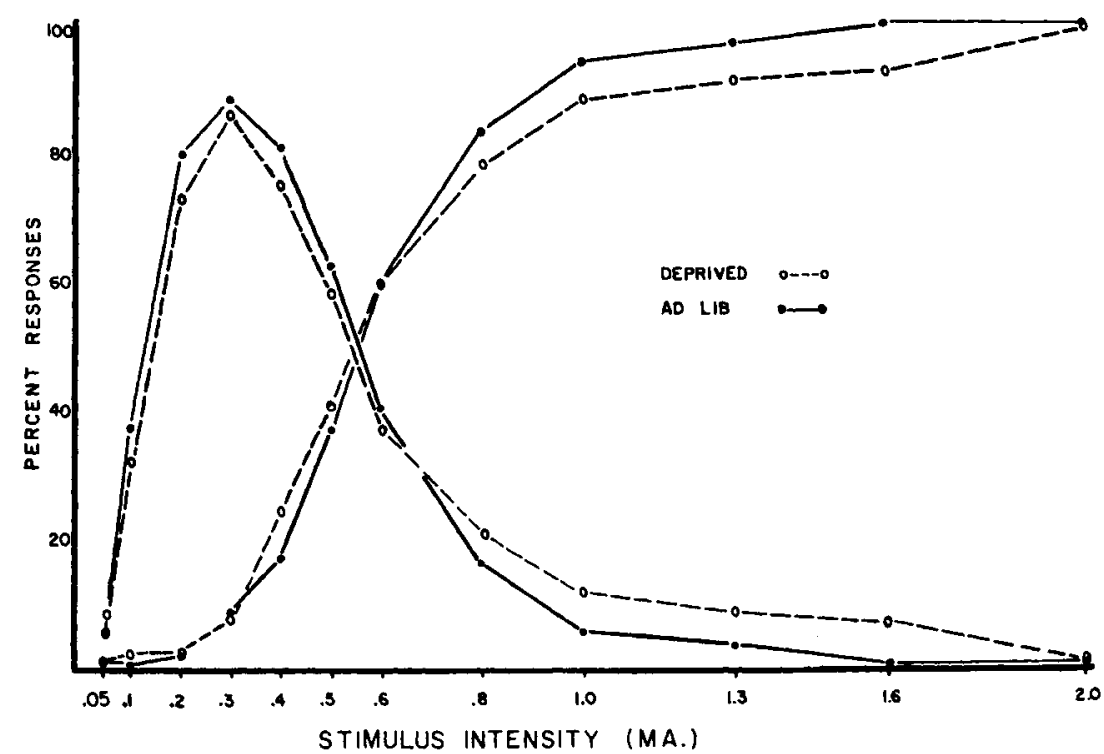

Psychon. Sci., 1966, Vol. $4(9)$
Fig. 1. Proportion of flinch and jump responses at each stimulus intensity, for deprived and nondeprived rats. Flinch response curves peak at left; jump response curves are asymptotic at right. 


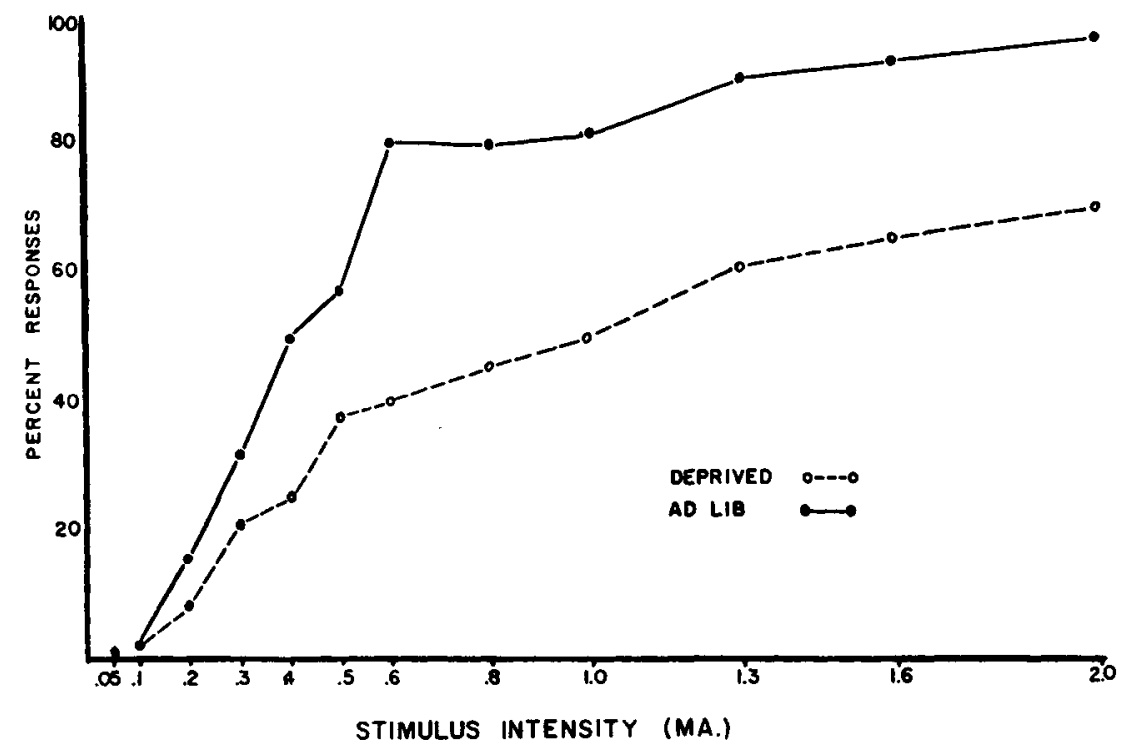

Fig. 2. Proportion of vocalization responses at each stimulus intensity, for deprived and nondeprived rats.

intensity. Visual inspection of these curves indicates no major differences between the deprived and sated groups, although there is some tendency for deprived Ss to give fewer jump and more flinch responses to stimuli of higher intensities. For each S, jump, flinch, and vocalization thresholds were computed by linear interpolation to the intensity at which the appropriate response was emitted on $50 \%$ of the trials. For the deprived group, the average flinch threshold was .15 ma, which was not significantly different from the sated group's threshold value of .14 ma ( $t=.90 ; p>.05)$. The average jump threshold was .54 ma for both groups.

Figure 2 presents the percentage of vocalization at each stimulus intensity. It is evident that, for vocalization, there are large and consistent differences between the groups, with deprived Ss giving fewer vocalization responses at each intensity level. The average vocalization threshold for the deprived group was $.88 \mathrm{ma}$, which was significantly different $(t=2.89 ; p<.01)$ from the average vocalization threshold of $.44 \mathrm{ma}$ for the sated group.

Since the deprived Ss ranged from $70-83 \%$ of original body weight when tested, a correlation coefficient was obtained to determine if weight variations within this range were related to amount of vocalization. The $r$ for per cent weight loss and total amount of vocalization, was -.69 , which indicated a significant correlation between these variables $(t=3.57 ; p<.01)$.

\section{Discussion}

Despite several differences in procedure, the results of the present study, with respect to sated Ss, are in close agreement with the findings of Kimble (1955) and Harvey \& Lintz (1965). The present use of a vocalization category provided an ordering and spacing of flinch, vocalization, and jump thresholds which was virtually identical to those of Harvey and Lintz.
Like the Griffiths (1962) study, the present investigation provides no evidence for the suggestion that deprived Ss are more sensitive to shock. However, except for vocalization, the present study also suggests that they are not less sensitive than sated animals. Moreover, the present vocalization results may provide an explanation of Griffiths' findings of higher thresholds for deprived Ss. Since Griffiths defined the S's response in terms of vocalization and vigorous reactions, his finding that hungry Ss are less reactive to shock may only reflect differences in vocalization, for which the threshold is markedly lower in sated Ss in contrast to deprived Ss.

The obtained correlation of $\mathbf{- . 6 9}$ between weight loss and vocalization, despite the restricted weight loss range, indicated that weight loss is a strikingly influential variable in the determination of vocalization to shock. It would appear that this influence is not due to inanition, since inanition would also be expected to influence flinch and jump thresholds. In addition, all deprived Ss seemed healthy and vigorous throughout the experiment. Finally, Moskowitz (1959) found an increase in running wheel activity in the albino rat, with up to $40 \%$ weight losses.

\section{References}

Griffiths, W. J. Effect of food and water deprivation on shock tolerance of albino rats. Psychol. Rep., 1962, 11, 163-166.

Harvey, J. A., Lintz, C. E, Lesions in the median forebrain bundle: delayed effects on sensitivity to shock. Science, 1965 , $148,250-252$.

Kendler, H. H. Motivation and behavior. In D. Levine (Ed.), Nebraska symposium on motivation. University of Nebraska Press: Lincoln, 1965.

Kimble, G. A. Shock intensity and avoidance learning. $J$. comp. physiol. Psychol., 1955, 48, 281-284.

Moskowitz, M. J. Running-wheel activity in the white rat as a function of combined food and water deprivation. J. comp. physiol. Psychol., 1959, 52, 621-625. 